\title{
Germanium and silicon isotope investigations in Main-Group and Eagle Station pallasites.
}

\author{
BÉATRICE LUAIS ${ }^{1}$, ZHENGBIN DENG ${ }^{2,3}$, JOHAN \\ VILLENEUVE $^{1}$ AND DAMIEN CIVIDINI $^{1}$ \\ ${ }^{1}$ Université de Lorraine, CNRS, CRPG \\ ${ }^{2}$ University of Copenhagen \\ ${ }^{3}$ Université de Paris, Institut de physique du globe de Paris,
} CNRS

Presenting Author: luais@crpg.cnrs-nancy.fr

Pallasites are differentiated meteorites composed of $\mathrm{Fe}-\mathrm{Ni}$ metal, silicate (olivine \pm pyroxene), \pm accessory phases, originating from early differentiated planetesimals $(<5 \mathrm{Ma}$ after CAIs). Whether they would represent metal and silicate in equilibrium at core-mantle interface or at shallower depth, or the result of impact and subsequent mixing of olivine and metal from differentiated bodies, remains debated. To test impact hypothesis for pallasite formation, two fundamental aspects of metal-silicate equilibrium need to be addressed, namely volatile-siderophile element enrichment/depletion in metal and olivine, and the direction of metal-silicate isotopic fractionation. We investigate the elemental and isotopic behaviour of germanium $(\mathrm{Ge})$, moderately siderophile and volatile, coupled to silicon with chemical affinities to Ge.

High-purity fractions of metal and $>1 \mathrm{~g}$ of olivine have been separated from Main-Group Pallasites (Imilac, Esquel, Brahin, Fukang, Brenham, Seymchan) and Eagle Station Pallasite. Highprecision measurements of Ge contents in olivine using ICP-MS standard addition method, Ge isotopes in olivine and metal using MC-ICPMS (CRPG [1]), and Si isotopes in olivine using MCICPMS (IPGP) and SIMS (CRPG) have been conducted.

The unexpected very low Ge contents in olivine at tens of $\mathrm{ppb}$ level, and the 45-56 ppm Ge contents in metal give high $\mathrm{D}(\mathrm{Ge})_{\text {metal-silicate }}$ of 1066-2086 for MGP and lower at 1013 for Eagle Station. Calculated $f \mathrm{O}_{2}$ values for MGP (IW-0.6) and Eagle Station (IW-0.4) indicate slightly reduced conditions, but disagree with previous oxidized $f \mathrm{O}_{2}$ determination for ESP $(\mathrm{IW}+0.5)$ [2]. The Ge isotope signatures distinguish the MGP $\left(\delta^{74} \mathrm{Ge}_{\text {olivine }}=+0.16 \pm 0.16 \%\right.$ o, $\delta^{74} \mathrm{Ge}_{\text {metal }}=+0.97 \pm 0.14 \%$ o, $\left.2 \mathrm{SD}\right)$, and the ESP with heavier isotopic values $\left(\delta^{74} \mathrm{Ge}_{\text {olivine }}=+2.36 \%\right.$, $\delta^{74} \mathrm{Ge}_{\text {metal }}=+3.42 \pm 012 \%$ o), which inversely correlate with strong negative $\delta^{17} \mathrm{O}$ values in ESP [3]. We measure similar $\delta^{30} \mathrm{Si}_{\text {olivine }}$ in MGP (-0.56 to-0.83\%o) and ESP (-0.54,-0.76\%), both $\delta^{30} \mathrm{Si}_{\text {olivine }}$ and $\delta^{74} \mathrm{Ge}_{\text {olivine }}$ being lower than in the silicate Earth. Positive, but high $\Delta^{74} \mathrm{Ge}_{\text {metal-silicate }}$ of +0.75 to $+1.08 \%$, in the same direction than the Earth system [1], suggests initial formation within the parent body. Later processes, as seen in ESP, would produce metal-silicate disequilibrium and heavy $\mathrm{Ge}$ isotope fractionation through evaporation at temperature lower than Si evaporation.

[1] Luais (2012), Chem Geol 334, 295-311.[2] Righter et al. (1990), GCA 54, 1803-1815.[3] Clayton \& Mayeda (1996), CGA 60, 1999-2017. 